\title{
«Señoritas en busca de nombre»: jerarquización de una profesión a través del léxico*
}

\author{
LORENA M. A. DE MATTEIS \\ Universidad Nacional del Sur
}

\section{INTRODUCCIÓN}

En la investigación de las voces de la aviación empleadas en las sociedades hispanoparlantes, dos hechos lingüísticos se hacen evidentes casi de inmediato al considerar las denominaciones de las diversas profesiones aeronáuticas. El primero de ellos es la variación léxica existente para designar al personal de vuelo que vela por la seguridad y comodidad de los pasajeros, tanto sincrónica como diacrónicamente, mientras que para la mayoría de los colectivos profesionales en este ámbito tal variación es limitada. Esta variación se refleja en alternativas que pueden ser mono- y pluriléxicas, de origen o tradición hispánicas o de préstamo, de género femenino y masculino, de sentido genérico o con matices semánticos de jerarquía, etc. El segundo hecho es que esta variación ha dado lugar a discusiones lingüísticas que reflejan consideraciones de tipo social y cultural relevantes en el estudio de las representaciones sociales de la aviación comercial.

Para considerar ambos aspectos en el estudio de este vocabulario, el lexicológico y el de las representaciones sociales, integramos aportes teóricos generales de la lexicología y la lexicografía y otros aplicados a la lingüística española (Fritz 1988, Medina Guerra 2003, Seco 2003, Lüdtke y Schmitt 2004). Asimismo, la lingüística de corpus y la estadística léxica (Baker 2006, Berber Sardinha 2009, Enrique-Arias 2009) sustentan nuestro abordaje de las frecuencias léxicas, las tendencias de uso y la extensión social de las distintas denominaciones. Por su parte, para considerar los ejes representacionales evocados por las voces consideradas se consideran los aportes del análisis crítico del discurso (Wodak y Meyer 2001, Wodak y Chilton 2005) y bibliografía específica sobre la problemática del género y su expresión lingüística en el léxico profesional (Lledó Cunill 2006).

${ }^{*}$ El trabajo se desarrolló dentro del proyecto Estilo(s) comunicativo(s) en la interacción verbal en español bonaerense: construcción de identidades, valores y creencias, dirigido por la Dra. Rigatuso en el Centro de Estudios Lingüísticos «Dra. M. B. Fontanella de Weinberg». Subsidio de Proyectos de Grupo de Investigación de la Secretaría General de Ciencia y Tecnología de la Universidad Nacional del Sur (P.G.I. 24/I191). Se benefició además de una beca para estancias de investigación del Consejo Nacional de Investigaciones Técnicas realizada en la Universidad de Granada en el año 2013.

LORENA M. A. DE MATTEIS, «"Señoritas en busca de nombre”: jerarquización de una profesión a través del léxico», Revista de Lexicografia, XX (2014), pp. 77-106

Fecha de presentación: 04/03/2014 Fecha de aceptación: 10/11/2014 ISSN: 1134-4539, e-ISSN: 2603-667. DOI: https://doi.org/10.17979/rlex.2014.20.0.3875 


\section{OBJETIVOS Y METODOLOGÍA}

Nuestro objetivo es dar cuenta de los factores que influyen sobre los cambios producidos en este sector del vocabulario español a partir del análisis léxico de fuentes documentales y de la consideración del debate metalingüístico sobre las alternativas. Intentaremos atender a la situación de la variación léxica en distintas variedades del español, desde la década de 1940 hasta la actualidad. Esta aproximación amplia se justifica en el carácter internacional de la profesión cuyas denominaciones nos interesan, pues la movilidad geográfica del personal y de los pasajeros trasladados se refleja en su lenguaje.

Para el análisis de las unidades léxicas hemos trabajado con fuentes documentales primarias y secundarias. Entre las primeras, los textos escritos y orales que conforman el corpus corresponden a distintas variedades del español, destacándose cuantitativamente las del español de la Argentina - con predominio de su variedad bonaerense- y del español peninsular - con predominio de su variedad castellana- De manera complementaria, se han incluido textos de Bolivia, Colombia, Chile, Cuba, Ecuador, México, Perú, Uruguay y Venezuela.

La tipología textual más representada es la del discurso periodístico —en todas sus manifestaciones escritas- . Asimismo, integran el corpus algunos libros de texto escolares y otras producciones infantiles, folletería de líneas aéreas, textos históricos y de marketing aeronáutico, novelas y relatos, blogs y sitios de internet, etc. Los textos orales, menos representados, corresponden también a programas periodísticos, entrevistas y encuestas realizadas en forma personal con hablantes que no participan del ámbito aeronáutico y a conversaciones espontáneas. Por último, cuando ha resultado necesario, recurrimos como complemento a los ejemplos proporcionados en los bancos de datos léxicos CORDE y CREA.

El análisis consistió en un relevamiento de todas las alternativas léxicas para la referencia a los tripulantes de cabina de pasajeros en el uso real de las comunidades hispanoparlantes representadas en nuestras fuentes ${ }^{1}$. En particular, en la consideración de sus actuales frecuencias de uso se trabajó con textos periodísticos de diarios, revistas y periódicos correspondientes al período 1990-2013 que se digitalizaron o se tomaron de los respectivos portales, y con algunos textos de blogs y foros de aviación que permiten apreciar los usos de hablantes de distintas comunidades. Los indicadores cuantitativos de frecuencia se generaron a partir de su procesamiento con la herramienta Wordsmith Tools v. 6.0 y, si bien no son valores absolutos, orientan sobre la extensión de uso relativa de cada expresión. En este sentido, la predominancia otorgada a los textos periodísticos obedece a que la prensa constituye un mediador importante para la introducción de usos semitécnicos de las voces (Fritz 1988:1623) y que su lenguaje es «sumamente representativo del lenguaje común» (Bosque 2010: LXXI).

${ }^{1}$ Dejamos de lado aquellas expresiones mencionadas como alternativas en los comentarios lingüísticos (v. sección 3) pero no constatadas en el uso (aviatriz, mayordoma, muchadavi - 'muchacha de aviación'-, provisora, etc.). 
Como fuentes secundarias, trabajamos con datos lexicográficos, empleando tanto los diccionarios accesibles mediante la plataforma del Nuevo Tesoro Lexicográfico de la Lengua Española (NTLLE) ${ }^{2}$, como el Diccionario del Español Actual (1999), el Diccionario de Uso del Español (2007) y el Diccionario de Habla de los Argentinos (2008), entre otros. Como referencia técnica, por último, apelamos al Manual para Traducciones Aeronáuticas (2007).

\begin{tabular}{|c|c|}
\hline MARCA & OCURRENCIAS \\
\hline--- & 0 \\
\hline-- & $1-250$ \\
\hline- & $251-500$ \\
\hline+ & $501-750$ \\
\hline++ & $751-1000$ \\
\hline+++ & $\geq 1001$ \\
\hline
\end{tabular}

\begin{tabular}{|c|r|r|}
\hline PAís & FUENTES & TEXTOS \\
\hline Argentina & 35 & 444 \\
\hline Bolivia & 3 & 3 \\
\hline Chile & 3 & 4 \\
\hline Colombia & 1 & 1 \\
\hline Cuba & 2 & 2 \\
\hline Ecuador & 2 & 2 \\
\hline España & 42 & 489 \\
\hline Estados Unidos & 1 & 1 \\
\hline México & 7 & 8 \\
\hline Paraguay & 1 & 1 \\
\hline Perú & 2 & 2 \\
\hline Uruguay & 2 & 2 \\
\hline Venezuela & 2 & 2 \\
\hline ToTAL & 103 & 961 \\
\hline
\end{tabular}

Tabla 1. Marcas de frecuencia para el corpus periodístico posterior a 1990

Los datos de frecuencia de uso, la información lexicográfica y los fragmentos ilustrativos del uso real se sistematizaron en una base de datos desarrollada con el sistema Toolbox. La presentación de estos datos (sección 2) incluye, para cada expresión, origen etimológico, formas alternativas, marcas gramaticales, definición, ámbito y frecuencia de uso, primer registro lexicográfico de la voz en un diccionario de lengua española ${ }^{3}$ y de la acepción aeronáutica — si no la hay, se indica con el signo $\varnothing-{ }^{4}$. Entre las marcas, el ámbito de uso se indica con «Endo.», cuando la prevalencia ocurre al interior de las organizaciones aeronáuticas, y «Exo.», cuando se registra un empleo generalizado en la sociedad. Si no se indica una preferencia es porque resulta admisible en ambos contextos sociales. Las frecuencias de uso actuales, por su parte, se expresan por referencia a las totales del corpus digitalizado, integrado por 961 textos (con 753846 tokens y 44383 types), tomados de más de 100 fuentes documentales distintas. Como todas las voces consideradas se ubican en la franja de frecuencia de 1-250 ocurrencias (tabla 1), sus frecuencias relativas se comparan entre sí (tabla 3$)^{5}$. En este

\footnotetext{
${ }^{2}$ Los diccionarios se citan por las claves indicadas en la sección de referencias.

${ }^{3}$ Descartamos en este trabajo las fuentes lexicográficas bilingües que pueden haber registrado una voz con anterioridad a su definición en algún diccionario de la lengua española.

${ }^{4} \mathrm{Si}$ la definición o la información etimológica está tomada en forma textual de algún diccionario, se indica la fuente entre corchetes. Caso contrario, se trata de una elaboración propia sobre la base de distintas obras o de la elaboración de los datos.

${ }^{5}$ En el mismo rango se ubican todas las designaciones de profesiones aeronáuticas, solamente superan estas frecuencias voces más generales como avión, volar, vuelo, etc.
} 
mismo sentido, la marca «desus.» indica que la expresión se empleó en algún momento del siglo XX pero que no se registra en la actualidad.

Los ejemplos ilustran el empleo de cada voz a lo largo del tiempo y destacan aquellos elementos centrales de las representaciones sociales que cada una evoca y refuerza en el uso cotidiano de las distintas comunidades hispanoparlantes, por lo que su análisis se organiza en torno a los ejes de las funciones laborales y el género de la profesión.

En relación con la discusión metalingüística sobre estas denominaciones y a fin de identificar los factores sociales que han influido sobre el hecho de variación, en la sección 3 se presentan algunos testimonios de escritores, periodistas y destacados filólogos españoles que han participado del debate, mostrando cómo se manifiestan en sus argumentos diversos aspectos y cambios en la representación social de esta actividad, incorporando como tercer eje de análisis el del prestigio social de la profesión.

\section{LAS PROFESIONES AERONÁUTICAS: DENOMINACIONES PARA LOS TCP}

En el marco de nuestra investigación, incluimos entre las profesiones aeronáuticas todas aquellas vinculadas con la operación de aeronaves. De esta manera y entre otros grupos profesionales, consideramos a los pilotos, los controladores aéreos, los despachantes, los mecánicos y, también, al personal que tiene directa relación con los pasajeros en vuelo. Este personal aeronavegante ha sido denominado de distintas maneras por la sociedad y las propias organizaciones aéreas y reguladoras. En este artículo, nos referiremos a ellos como tripulantes de cabina de pasajeros o, para abreviar, TCP, respetando de esta manera la denominación preferida por este colectivo profesional ${ }^{6}$.

Aunque desde los primeros vuelos dedicados a transportar personas tras la Primera Guerra Mundial hubo algún tipo de atención a los pasajeros, a veces en tierra, a veces a cargo del piloto, el copiloto o algún auxiliar, y de que los grandes dirigibles incluían un cuerpo de personas para asistir a los clientes, la profesión de TCP nació oficialmente en 1930 cuando la compañía estadounidense Boeing Air Transport contrató por primera vez un grupo de mujeres para cumplir dicha función. Estas nuevas profesionales debían ser jóvenes, cultas y, de preferencia, poseer formación en enfermería. En cuanto a su papel en la historia aeronáutica, y sobre la base del argumento comercial de base psicológica de que si las mujeres se animaban a volar no había razones para temer, puede sostenerse que las legendarias aviadoras de la década de 1920-1930 cedieron su lugar a estas mujeres en la promoción de la seguridad del transporte aéreo (Pavlovcic 2010:192). En un principio recibían una capacitación breve para el servicio del pasaje que, con el progreso acelerado de las aeronaves, fue ampliándose para incluir en el presente funciones más amplias de seguridad y, también, la representación de la autoridad del Comandante mientras este se encuentra en la cabina de vuelo.

\footnotetext{
${ }^{6}$ Las denominaciones sindicales en los distintos países americanos (por ejemplo, Asociación Argentina de Aeronavegantes, Sindicato de Tripulantes Auxiliares de Vuelo de Líneas Aéreas [España], Asociación Sindical de Sobrecargos de Aviación de México, etc.) constituyen datos adicionales no considerados en este trabajo por razones de espacio.
} 
En el nivel léxico, es interesante observar que la denominación inicial en inglés, (air) stewardess, derivaba del transporte marítimo y de la atención de las grandes casas. De manera similar, algunas denominaciones registradas en español, como sobrecargo, también permiten detectar la misma relación de continuidad entre ambas modalidades del transporte que, por un proceso metafórico, se conciben como formas diferentes de navegar, facilitando que las unidades léxicas de la náutica amplíen su significado al vuelo (de Matteis 2012). Además, la nueva profesión también determinó en español la adopción temporal de préstamos, la aparición de neologismos de diversa fortuna y la revitalización de voces que, aunque nunca habían dejado de utilizarse por completo, remitían a un pasado tan lejano que no parecían del todo apropiadas al progreso representado por la aviación en el siglo XX (de Matteis 2010). En un intento de encontrar una guía efectiva, la inquietud de quienes debían utilizar la expresión para promover la actividad aeronáutica motivó consultas explícitas a la Real Academia Española y, de esta manera, la iniciativa privada y la consulta a los académicos se tradujo, sobre todo en España ${ }^{7}$, en un debate interesante. Pero, con independencia de estas discusiones, el campo léxico en cuestión evolucionó movido por cambios sociales vinculados a los espacios laborales femeninos y masculinos y por fuerzas propias de las compañías aéreas, a medida que las condiciones de su trabajo se modificaban ${ }^{8}$.

Si descartamos las propuestas léxicas que nunca lograron extenderse en el uso social (nota 1), a la fecha hemos registrado poco más de una docena de expresiones alternativas en diversas regiones hispanoparlantes. Esta cifra incluye denominaciones genéricas $^{9}$ y otras que dan cuenta de la especialización de funciones y jerarquía existente entre los TCP como colectivo profesional: aeromozo, -a; asistente de vuelo; auxiliar de vuelo; azafato, -a; cabinera; comisario (de a bordo); (air) hostess; jefe de cabina; sobrecargo; (air) steward, -dess; purser; TCP; tripulante (de cabina (de pasajeros)).

En lo que sigue de esta sección, proporcionamos para cada una de ellas la información lexicológica y lexicográfica más relevante, así como los ejemplos de uso de cada acepción en un orden cronológico progresivo para destacar no sólo su pervivencia (o no) en los usos de las comunidades hispanoparlantes, sino también para considerarlas en contexto e identificar los elementos centrales de las representaciones sociales (Jodelet 1993) sobre esta actividad profesional que vehiculizan.

En la definición de las acepciones aeronáuticas de las voces recogidas en obras lexicográficas, seguimos en todo lo posible la más reciente, indicando su fuente entre corchetes. En caso contrario, elaboramos nuestra propia definición, por lo general, remitiendo a la denominación que al colectivo profesional le resulta más aceptable en

\footnotetext{
${ }^{7}$ No hemos podido encontrar materiales similares a los presentados en la sección 3 para otras variedades del español.

${ }^{8}$ Ejemplos de estos avances que competen al accionar de los TCP son, por ejemplo, la obligatoriedad de los cinturones de seguridad, el diseño de las puertas de emergencia, la presurización de las cabinas, etc.

${ }^{9}$ Casares advertía ya en 1950 que «una cosa es dotar de nombre específico a las servidoras del avión para efectos profesionales, crematísticos o administrativos y otra cosa es elegir el apelativo adecuado para dirigirse a ellas» (1950b: 3). En la actualidad, para dirigirse a los TCP suelen emplearse, todavía, las fórmulas de tratamiento cortés señorita, señora o señor.
} 
la actualidad en las distintas regiones hispanoparlantes, esto es, tripulante de cabina de pasajeros, expresión que, por su parte, recibe la definición más precisa ${ }^{10}$.

aeromozo, -a. ${ }^{11}$ (De AERO- y MOZA, y esta de or. inc.) ${ }^{12}$ aero-mozo. m. y f. Am. Exo.

Azafato o azafata de aviación (DRAE-1992)

Entre los registros lexicográficos, el DRAE, el NDA-ARG, DEA, DUE y VOX dan la entrada por la forma femenina y la definen, con algunas diferencias, como azafata, en forma femenina, por lo que hemos adaptado la definición actual del DRAE ${ }^{13}$. El DPD, por otro lado, se hace eco del hecho de que la profesión también sea ejercida en la actualidad por hombres, de forma que admite la forma masculina y es el único que, a la fecha, da la entrada incluyéndola. Hoy es voz de uso general en la comunidad y no de las organizaciones aeronáuticas. En cuanto al ámbito geográfico en el que se la emplea, y aunque la mayoría de los diccionarios reconozcan su origen y su ámbito como americano (el más preciso en este punto es el Vox, que la atribuye a América Central, Chile, Cuba, México, Perú y Venezuela), hemos podido constatar usos - no menciones- de la expresión también en España. Sin embargo, estas ocurrencias son raras en la actualidad, como observa el DEA, y se refieren a realidades americanas, de tal manera que podemos corroborar que nunca alcanzó una gran extensión social de uso en este país:

(1) El Mundo 20080904: Aeromozas de Aerolíneas Argentinas y Austral siguen el debate de los senadores argentinos desde fuera del Congreso. (Foto: EFE) («El Parlamento argentino aprueba la compra de Aerolíneas por parte del Estado») $)^{14}$.

En cuanto a sus primeros empleos, el más antiguo que constatamos en el español bonaerense ocurre en un chiste publicado en Revista Aeroposta, publicación dedicada a sus pasajeros por la compañía Aeroposta Argentina, propulsora de la aviación en la Patagonia:

(2) Revista Aeroposta, 1938, ํ2, s/p: Fué a pedir la mano de su novia y el padre le dijo: / — Cómo se atreve Vd. a dar este paso con la reputación de haragán que

${ }^{10}$ En esta decisión no nos regimos por la novedad ni por un intento de precisión terminológica sino que seguimos, de alguna manera, la sugerencia de Casares (ibidem): «Puesto que no hay obstáculo, ni semántico ni gramatical, para que cualquiera de las palabras usuales antes citadas asuma una nueva acepción específica para el caso de que se trata, creo que por parte de cuantos hemos intervenido en el pleito sería un gesto de obligada galantería brindarnos a aceptar el fallo de las interesadas, confiados en su buen gusto».

${ }^{11}$ Pese a la prevalencia del personal femenino, las voces que registran una forma masculina y una femenina se enuncian por la forma masculina de acuerdo a las pautas lexicográficas habituales.

${ }^{12}$ Salvo indicación contraria, las etimologías de las voces españolas corresponden al DRAE. Como hemos señalado, la fuente de la definición se indica entre corchetes y las ocasionales modificaciones se explicitan en el texto.

${ }^{13} \mathrm{El}$ artículo actual del DRAE será enmendado para la próxima edición y se dará la entrada por ambos géneros, con la definición: 'Azafato de aviación', aunque en la etimología se seguirá rescatando el origen de la forma femenina.

${ }^{14}$ La fecha de los ejemplos sigue la de la sistematización informática adoptada: año, mes, día. Cuando los ejemplos actuales se toman de las ediciones en línea, no se indica número de página. Si el ejemplo está tomado de una fuente secundaria o de un corpus de referencia, se lo indica entre corchetes al principio. La doble barra (//) representa separación entre párrafos en el original. Los destacados en los ejemplos y en las citas nos pertenecen, a menos que se indique lo contrario. 
tiene?// -Es que he cambiado mucho. Ahora trabajo y hasta mis patrones me ponen por las nubes. // —.... ? // —Sí, trabajo de aero-mozo («Humor aéreo»).

De la novedad de la expresión en estas primeras décadas de servicio a bordo sigue dando cuenta no sólo la variante escrita con guión en el fragmento precedente sino las comillas que se aprecian en este ejemplo mexicano de 1952:

(3) El Informador 19520323: Los cuatro supervivientes, dos hombres y dos mujeres, resultaron heridos. Tres de ellos pasajeros y la cuarta persona era una "aeromoza", la señorita A. J. G. Gautier, habiendo sido todos llevados al hospital de la Fuerza Aérea de los Estados Unidos en el aeropuerto («Tragedia aérea en Alemania»).

La morfología de aeromoza sugiere una asociación con la idea de servicio y, quizá también, de servidumbre, como también azafata y camarera (v. infra). De esta manera, todas estas voces aluden a la primera de las funciones que, a lo largo del tiempo, han definido esta profesión: atender al confort de los viajeros durante el vuelo.

Por otro lado, esta voz evidencia una fuerte relación entre la actividad y una idea de femineidad que reconoce en la independencia un nuevo valor. Así, por ejemplo, el periodista español A. Díaz-Cañabate observaba en 1947 que esta cualidad era uno de los obstáculos que existían para casarse con una azafata, en un texto que sugiere lo que la profesión representó en el marco de la lucha por los derechos femeninos en el siglo XX:

(4) $A B C$ 19470629, p 9: ¿Pero quién es el guapo que se casa con una "aeromoza”? ¡Unas mujeres de tanta altura, que están siempre en las nubes! ¿Cómo se va a acostumbrar la "aeromoza" a un pisito vulgar, aunque sea el ático de un rascacielos, ellas, habituadas a los seis mil metros de altura, a los horizontes inmensos de los cielos y los mares, a saltar de un mundo a otro, como quien salva de un brinco un arroyuelo? ¿Cómo proponerles para distraerse un viajecito el domingo a Cerdecilla, a ellas, que están acostumbradas a pasar un domingo paseando por la avenida de Mayo, de Buenos Aires, y el lunes se dan una vuelta por las pirámides de Egipto? Imposible. Porque si se retiran de su oficio, malo. La nostalgia de los inmensos horizontes es incurable. Si continúan volando, peor aún. El marido les diría: // -El miércoles iremos al "cine". // — ¿El miércoles? Lo siento, pero no puedo. El miércoles estaré en Honolulú. // ¿Mas para qué necesitan casarse las "aeromozas"? Son las novias del cielo. Son bellas como las nubes, per, como ellas, inabordables para los que aun no nos hemos decidido a prescindir del asfalto. Están acostumbradas a los guiños de los luceros y, francamente, con los luceros no hay competencia posible. Con el tiempo, se podrán casar en Marte. En la Tierra, no. // “"Aeromoza”, linda palabra recién nacida! («Las «aeromozas»»)).

Aunque la actividad ya no sea privativa de las mujeres, la femineidad y la independencia constituyen desde el principio elementos centrales de la representación social de la profesión y se reflejan todavía, en los siguientes textos periodísticos de Cuba y Venezuela, ambos de fecha reciente:

(5) Prensa Libre 20131108: [...] Hace unas décadas era un lujo viajar — casi una extravagancia- Hoy son mareas humanas. Antes, la atención personalizada era la norma. Las aeromozas eran tan mozas, que dejaban un aire de secreta atracción cuando pasaban a tu lado atendiendo el menor deseo con una sonrisa en la boca y un olor a perfume de misteriosa fragancia («Yo vuelo, tú vuelas»).

(6) El Nacional 20130310: ¡Bienvenidos a bordo! Con ese gentil saludo, repetido en una extensa lista de idiomas, las aeromozas de las líneas aéreas reciben a los pa- 
sajeros. Ese saludo es — quizás — uno de los hitos más importantes de la travesía, pues además de ser un ameno protocolo de bienvenida, les recuerda a los viajeros que ellas son las guías cuando se presenta alguna duda o situación de emergencia. Pero ser azafata también es un trabajo dotado de cierto halo de fantasia y misterio, un rol que durante décadas contribuyó a la independencia y reconocimiento de la mujer («La glamorosa vida de las aeromozas»).

asistente de vuelo. (Del lat. ASSISTENS, -ENTIS, del ant. part. act. de ASISTIR. [DRAE]). com. tripulante de cabina de pasajeros. U. t. c. adj. - -

Hasta donde llega nuestro conocimiento, esta expresión compleja no ha sido recogida en ningún diccionario. Sin embargo, usada como adjetivo o como sustantivo la hemos registrado desde la década de 1970. El siguiente ejemplo peninsular, en el que aparece como adjetivo, sugiere la equivalencia semántica del sintagma personal asistente de vuelo con la voz azafata:

(7) $A B C 19790328$, p. 37: Hoy se cumple el día número treinta y cinco desde que el personal asistente de vuelo de la compañía Alitalia inició una huelga. [...] En una asamblea tenida ayer, las azafatas de Alitalia han propuesto volar entre abril y junio en un estado de «conflictividad permanente» («Treinta y cinco días de huelga en Alitalia»).

Como sintagma nominal, la expresión permite la referencia a los profesionales de ambos sexos, como se aprecia en el texto de F. Peña, humorista argentino que fue TCP:

(8) Y pasemos a la última de las funciones, la seguridad, que es en realidad la principal. Aunque te parezca mentira, es fundamental el rol de un asistente de vuelo en un avión. Lo primero que hacemos al subir, mientras los pasajeros no están a bordo, es verificar que estén presentes y en condiciones todos los elementos de emergencia (Peña, 2007: 91).

La necesidad de una denominación común para hombres y mujeres, que elimine las connotaciones sexistas, es reflejo tanto de la lucha contra los estereotipos de género asociados a la actividad como de una evolución profesional dentro de las organizaciones aéreas que admiten tanto a mujeres como a hombres, otorgándoles hoy a ambos posiciones de autoridad. En este proceso reivindicativo, podría suponerse que la expresión constituye una denominación limitada a este ámbito y por eso resulta de interés su aparición en el uso social general, por ejemplo, en textos periodísticos y narrativos como los siguientes de un diario español y de una novela de la escritora argentina A. Zina:

(9) La Vanguardia 20111129: Según informa "The Business Times", un asistente de vuelo que estaba sentado frente a la zona de pasajeros ha visto cómo un pasajero se mostraba inquieto en su asiento y trasteaba en el bolsillo de sus pantalones («Un iPhone provoca un pequeño incidente en un avión que viajaba a Sydney»).

(10) En el curso de capacitación nos contaron que las primeras asistentes de vuelo fueron ocho enfermeras inglesas que pasaron a la historia como las Sky Girls. Entre ellas viajaba Ellen Church, una joven fanática de los aviones, que en 1930 convenció a los directores de la Boing (sic) Air Transport de contratar mujeres para los vuelos comerciales. [...] El cielo es un misterio habitado por ángeles, constelaciones, truenos, satélites, agua condensada. Y ahí estamos nosotras, atravesándolo como flechas. ;SHUMMMMMMMMMMMM! Uniendo un punto del otro con otro y con otro y con otro (Zina 2011:15-16). 
Según muestran la cita de Peña y la nota de La Vanguardia, esta expresión puede asociarse con una concepción endo-institucional que valora la función de seguridad cumplida por estos aeronavegantes evidenciando una profesionalización de la actividad. En tales fragmentos no se aprecia la cuestión del sexismo. En cambio, en el texto de Zina no hay alusiones a las funciones profesionales y sí se reitera la representación esencialmente femenina de la actividad, aunque esta observación debe matizarse por ser consecuencia lógica de la voz de un personaje femenino.

auxiliar. (Del lat. AUXILIĀRIS). com. Persona destinada en los aviones a la atención de los pasajeros y de la tripulación [DRAE]. Frec. con los compl. $\sim$ de a bordo o de vuelo. - - RAE A $1726 \rightarrow$ RAE M 1983.

Aunque esta voz puede aparecer sola, es más frecuente acompañada por complementos. Con el complemento de a bordo no ha sido registrada en los diccionarios pero sí aparece en glosarios aeronáuticos en línea, por ejemplo en el blog «Secretos de azafatas» (consultado en 2008): «Es el verdadero nombre de las azafatas. La palabra azafata no se usa en el ambiente aeronáutico. Auxiliar se usa tanto para hombres como para mujeres tripulantes». Esta «definición» destaca el rechazo por azafata al tiempo que enfatiza la posibilidad que brinda auxiliar para incluir a todos los tripulantes sin distinción de sexo. En cambio, con el complemento de vuelo, más frecuente en nuestro corpus, se la ha incluido en los diccionarios DRAE, DEA, DUE y VoX, además de diversos glosarios, lo que sugiere su empleo tanto en el seno de organizaciones aéreas como en el uso general de las comunidades hispanoparlantes. Como asistente de vuelo, estas denominaciones permiten eliminar el problema del sexismo lingüístico.

En cuanto a su distribución geográfica, auxiliar de a bordo se detecta a ambos lados del Atlántico desde la década de 1950:

(11) La Nación 19571018, p. 3: Todos quienes forman Transcontinental han sido seleccionados en cada una de sus especialidades entre los mejores: pilotos, técnicos, personal administrativo, auxiliares de a bordo, asesores, gerentes y gerente general, representan una cantidad de experiencia inigualable, puesta por completo al servicio de la aviación. («1956 -18 de octubre- 1957. Transcontinental en su primer año de vida...»)

(12) ABC 19571029, p. 17: Auxiliar de a bordo D. Alfonso del Corral Felipe, de veintinueve años, casado, con 6.800 horas de vuelo y cinco años de servicio en la Compañía. («Un avión de la línea Tánger- Madrid se estrelló ayer a las seis de la tarde, cerca de Getafe»)

Pese a que los ejemplos evidencian la apertura hacia ambos sexos en el desempeño de esta profesión, es necesario destacar que el estereotipo femenino se reitera hoy incluso cuando se emplea esta voz. Así, en el fragmento 13 resulta interesante comparar el empleo genérico de auxiliar de a bordo - acompañado de los adjetivos argentino, nativo y naturalizado - con las dos voces femeninas del título de la nota, azafatas y anfitrionas:

(13) La Nación 20031228: Los requisitos para presentarse como auxiliar de abordo (sic) en Aerolíneas Argentinas son: ser argentino nativo o naturalizado, vivir en un radio de $30 \mathrm{~km}$ de la Cap. Fed., nivel intermedio de inglés, estatura 1,60 m (mujeres) y 1,70 (hombres), tener licencia de TCP (no excluyente), certificado psicofisiológico vigente y saber nadar. («Azafatas, anfitrionas de los cielos»). 
El contraste entre la expresión común y las formas femeninas pone en evidencia que, aunque puedan emplearse denominaciones no sexistas y el aviso permita deducir que el sexo femenino no es un requerimiento, el estereotipo social dominante sigue siendo el de la tripulante femenina.

De manera similar, esta imagen se refuerza por la promoción del atributo de belleza femenina en 14, aspecto que constituye una constante en la representación de las auxiliares desde el inicio de la actividad:

(14) La Nación 20120324: La bonita auxiliar de a bordo se transforma en una dama seria que manda abrochar los cinturones y apagar los aparatos electrónicos. («48 horas en San Pablo»).

Por último, en su empleo como adjetivo, estas expresiones califican a un sustantivo más general como tripulación o personal, como en el siguiente texto de un diario patagónico:

(15) La Opinión Austral 20120818: El avión había partido de la India con destino a Gran Bretaña, y al descender en Viena y según el relato de los pasajeros, el personal auxiliar de vuelo les informó que se quedarían varados hasta que pudieran recaudar 31.000 dólares para financiar el resto del viaje hasta Birmingham. («Air France pide dinero a pasajeros de un vuelo para comprar combustible en Siria»).

azafato, -a. (De AZAFATE, y esta del ár. SAFAT, 'cesta de mimbre'). m. y f. Exo. Persona encargada de atender a los pasajeros a bordo de un avión [DRAE]. - - RAE A $1726 \rightarrow$ RAE U 1956. 2. f. Empleada de compañías de aviación, viajes, etc., que atiende al público en diversos servicios [DRAE]. - - - DRAE S-1970

De origen árabe, esta voz posee una larga tradición en la lengua española en su forma femenina hasta que en el DRAE de 1956 se reconoce una nueva acepción, la de 'Camarera distinguida que presta sus servicios a bordo de un avión'. Además de aparecer con distintas definiciones en todos los diccionarios posteriores, el DRAE S de 1970 incorpora el desempeño en otros medios de transporte y una tercera acepción referida a la 'empleada de una empresa de aviación que cumple diversos servicios'. Ambas acepciones se conservan en el DRAE actual, del que mantenemos la definición para la primera aunque añadiendo el sustantivo «persona» a fin de evitar la referencia a uno u otro sexo, tal como lo hace el artículo enmendado para la próxima edición del diccionario ${ }^{15}$.

En lo que hace a la segunda acepción, citamos la definición del DRAE sin modificar pues no hemos constatado en nuestro corpus la referencia a un empleado de sexo masculino (aunque no habría razón que lo impida). Sin embargo, cabe aclarar que para esta acepción solo hemos registrado el sintagma azafata de tierra, con el complemento clarificador. En tal sentido, los sintagmas azafata de tierra y azafata de congresos dan cuenta de la ampliación semántica de la voz a lo largo del siglo XIX y XX, sobre todo en el español peninsular, pues lo análogo de algunas de sus funciones hace necesario distinguirlas de las que se desempeñan en el aire. Así, el DMILE-1983 es el primer diccionario que agrega una acepción para las azafatas de congresos. El DRAE actual, antes de la acepción

\footnotetext{
${ }^{15}$ Como en el caso de aeromozo, - $a$, el artículo enmendado para la próxima edición del DRAE incluye las dos formas genéricas del sustantivo en todas las acepciones a excepción de la original.
} 
original de la voz, incluye la definición 'Muchacha que, contratada al efecto, proporciona informaciones y ayuda a quienes participan en asambleas, congresos, etc.'. En todos los casos, como se ve, se considera el sustantivo de género femenino.

En relación con la forma masculina azafato, el DPD señala:

$\mathrm{Al}$ ser labores tradicionalmente desempeñadas por mujeres, hasta no hace mucho solo existía la forma femenina azafata; dado que hoy también las realizan hombres, se ha creado, y es plenamente válido, el masculino azafato.

En cuanto a sus ámbitos de uso, aunque sigue siendo la expresión más habitual en la sociedad, es rechazada por las organizaciones aéreas tanto por limitar las funciones profesionales a las del servicio al pasajero como debido a sus posibles connotaciones sexistas.

Desde una perspectiva histórica, por otro lado, el empleo aeronáutico de azafata se registra desde la segunda mitad de la década de $1940^{16}$ hasta la actualidad:

(16) La Vanguardia Española 19471123, p. 3: Entre los pilotos civiles a los que ayer se entregaron los títulos, figura la señorita María Josefa de Ugarte y Domingo Arana, que ha terminado recientemente el curso organizado por el Aero Club de Madrid. Es esta la primera mujer española que recibe el título de aviador. // En la actualidad presta sus servicios como azafata en los aviones de la «Iberia» («La primera mujer española con el título de aviadora»).

(17) La Vanguardia Española 19480810, p. 2: Han llamado poderosamente la atención las amplísimas proporciones de estos aparatos, que dan al público una sensación total de seguridad y confort extraordinario, uniéndose a ello la información recogida de que la Compañía, velando por la comodidad del pasaje, va a dotar a dichos aviones de azafatas que proporcionarán al público la información y detalles de vuelo («Inauguración de nuevas líneas aéreas para viajeros y carga»).

Estos ejemplos muestran el lugar dado a la mujer en las compañías aéreas de mediados del siglo XX y, una vez más, que la función original se limitaba a proporcionar comodidad e información útil al pasaje.

La novedad de la voz continuaba siendo señalada en la década de 1950, durante la que el transporte de personas entró en una etapa de desarrollo acelerado en la vida social:

(18) ABC 19590626, p. 9: Al mismo tiempo que a las "azafatas", los amabilísimos organizadores de la "Hospitalidad azul" de Rímimi han entregado, por sorteo, quince estupendas copas de plata a las Compañías aéreas que han acogido la invitación. El proyecto del "Ente Turístico" es crear una espléndida residencia en la ciudad romañola, donde cada año puedan pasar gratuitamente sus vacaciones, por turno, las "hostess" aéreas de todo el mundo. Rímimi será, pues, la ciudad de reposo y de alegre diversión de las gentilísimas muchachas que cuando subimos en un avión saben ofrecernos con una sonrisa y una simpática palabra el optimismo necesario para no pensar más que en las delicias del vuelo («Concentración en Rímimi de «azafatas» aéreas del mundo»).

\footnotetext{
${ }^{16}$ Mientras que en 1934 Swissair se convierte en la primera empresa europea en incorporar este
} personal, la española Iberia lo hace a fines de 1946. A fines de esta década ocurre lo propio en la compañía Aerolíneas Argentinas. 
Las comillas destacan todavía el carácter neológico de la nueva acepción de azafa$t a$, coexistente en este fragmento con el anglicismo hostess, como un equivalente semántico también resaltado en el texto. El artículo destaca tanto las funciones básicas de la profesión y la tranquilidad que proporcionan las tripulantes como diversas cualidades (gentilidad, belleza, simpatía) que refuerzan el estereotipo femenino de la profesión. De manera análoga, los ejemplos argentinos evidencian la centralidad de la función de atender y brindar información turística ${ }^{17}$ :

(19) Guía Argentina de Tráfico Aéreo $\mathrm{N}^{\circ} 221,196610, \mathrm{~s} / \mathrm{p}$ : Estamos en condiciones de ir a París, a Nueva York, a Londres. Nuestros pilotos saben de memoria cómo llegar, nuestras azafatas podrán informarle al detalle cómo pasarlo mejor en cada uno de estos lugares («Vamos adonde más nos necesitan», publicidad de Austral).

Como hemos visto en relación con otras expresiones, las cualidades asociadas con el estereotipo profesional femenino se reproducen en los usos contemporáneos de azafata aunque pueden asociarse ya no con el servicio sino con su función de seguridad, como lo muestra el siguiente fragmento literario:

(20) No soy gorda. Tengo el peso adecuado pero me cuido, unos kilos de más pueden significar vacaciones obligadas a base de verduras, frutas y merluza congelada. Una azafata excedida de peso no puede moverse fácilmente a lo largo de los pasillos del avión en una sola hilera y mirando hacia delante. Tampoco puede pasar por la ventanilla de emergencia. Una azafata no puede engordar (Zina, 2011:25-26).

Del empleo de la forma masculina, por otro lado, hay indicios desde la década de 1980 (cf. el título de nota del ejemplo 44) y resultan cada vez más frecuentes:

(21) La Nación 20131001: Cuando subimos al avión, ahí estaba él para recibirnos y ahí entendimos que no era el piloto, si no nuestro comisario de abordo, bah, nuestro azafato estrella («La insólita experiencia de viajar con Guido Süller como azafato del avión», énfasis en el original).

Como se ve, aunque se admita su validez, azafato sigue resultando forma extraña — de ahí el énfasis del DPD en relación con la legitimidad de la forma- y por eso aparece entre comillas o en itálicas, tal como ocurría en los primeros usos de la forma femenina.

cabinera. (De CABINA). f. Col. y Ec. Exo. Auxiliar de vuelo [DRAE]. - - DRAE-

1970

Registrada lexicográficamente en 1970 y restringida en su empleo a algunos países, esta expresión aparece testimoniada por una nota periodística española ya en 1959 y se utiliza todavía, al exterior de las organizaciones aéreas, aunque los ejemplos disponibles en textos escritos sugieren que su frecuencia de uso no es elevada (cf. tabla 3 ).

Los escasos contextos en los que la encontramos no ofrecen información muy clara con respecto a la representación social de esta profesión, aunque sí se puede señalar que no hemos constatado una forma masculina:

(22) El Universo 20131013: Ojalá, eso sí, el piloto haya recibido un curso intensivo para que, jamás de los jamases, anuncie, con voz temblorosa, desde la cabina:

${ }^{17}$ En tal sentido, el turismo es una actividad comercial desarrollada en gran medida gracias al transporte aéreo y en forma simultánea con aquel (Wallingre 2003). 
"Señores pasajeros, asegúrense los cinturones porque estamos entrando a una zona de turbulencia". Híjoles, ahí sí el excelentísimo señor presidente de la República se ha de levantar furiosísimo, ha de ordenar a las cabineras que le abran la puerta para aplacar él mismo la turbulencia, se ha de desanudar la corbata, se ha de abrir la camisa y ahí sí se friega el viaje («Revolución al vuelo»).

Por otro lado, esta voz se destaca entre las restantes pues como derivación de cabina es la única que designa al profesional solo por referencia al lugar donde se desempeña.

camarero, -a. (Del lat. CAMARARǏUS, CAMERARIUS, de CÁMARA). m. y f. Tripulante de cabina de pasajeros dedicado a la atención de los pasajeros. - - NEBRIJA $1495 \rightarrow$ DUE

Incluida, según el NTLLE, entre los registros lexicográficos de la lengua española en 1495, en la actualidad solo el DUE explicita una relación semántica con la voz azafata, señalando de esta manera su posible aplicación al ámbito aeronáutico. En los restantes diccionarios debe deducirse que el avión constituye un ámbito análogo al de otros establecimientos donde las personas son servidas por el personal.

Como aeromozo, - a y azafato, - $a$, esta denominación destaca la idea de servicio a los pasajeros y, como a la mayoría de las expresiones, se registra desde la década de 1950. En una publicidad de la línea aérea TAN-APSA, el texto expresa con esta voz la orientación de las compañías aéreas hacia la satisfacción de sus potenciales clientes ${ }^{18}$ :

(23) La Nación 19571001, p. 11: - Veteranas tripulaciones americanas con dos camareras («TAN-APSA», publicidad).

Por otro lado, en la década de 1960, es posible que el empleo de la forma masculina sirviera a los efectos de distinguir entre los tripulantes femeninos y masculinos, como lo sugiere el siguiente ejemplo que resume la función de ambos en el sintagma «servicio de atención al pasaje»:

(24) $A B C 19670725$, p. 32: El avión del Papa estará comandado por el capitán Olive Shilson, ayudado por el primer oficial Charles Bonini y por el segundo oficial Frederick Thompson. Comisario de a bordo será John Salmini, y el servicio de atención al pasaje estará a cargo de las azafatas Joan Disse, Carole Osche, Rosa Magrustsch, Janina Zyla y de los camareros Joseph Pasquini y Mario Dominicis («Reformado el avión en el que viajará el Papa»).

Esta alternativa, poco frecuente en nuestro corpus pero válida, evita la forma femenina de azafata sin apelar a la voz comisario que, entre sus connotaciones alude no solo al sexo del tripulante sino que también puede suponer una diferencia jerárquica. De cualquier manera, se trata de una voz poco específica pues puede aplicarse en distintos ámbitos sociales - cafés, bares, barcos-. Es de destacar, por último, que es la única que podría utilizarse también como vocativo.

${ }^{18}$ Es difícil valorar, a través de ejemplos como el precedente, si en la década de 1950, a la que corresponde el ejemplo, se trataba de una forma empleada por igual al exterior y al interior de las organizaciones aéreas. 
Los usos actuales son muy escasos y, a título de ejemplo, el siguiente se corresponde con la descripción de un vuelo realizado en 1932, lo que sugiere un empleo estilístico de la expresión:

(25) Los Andes 20120715: Robinson caminó hacia el avión con el radiotelegrafista Myers y el camarero Wood, minutos después subieron sus 6 pasajeros y las 6.30 horas, el trimotor de la Panagra llamado "San José" partió hacia la cordillera («El avión que se tragó la cordillera»).

comisario, -ria. (Del b. lat. COMMISSARǏUS, y este del lat. COMMISSUS, part. pas. de COMMITTĚRE, 'cometer'). m. y f. Tripulante de una cabina de pasajeros con mayor antigüedad y al que responden los restantes tripulantes, cuyas tareas supervisa.. Frec. con el compl. $\sim$ de a bordo. $\rightarrow$ jefe, -a de cabina. - - DRAE-1780 $\rightarrow \varnothing$ 2. m. Exo. Tripulante de cabina de pasajeros de sexo masculino. -- DRAE-1780 $\rightarrow \varnothing$

Si bien la voz tiene más de dos siglos en los registros lexicográficos, las acepciones aeronáuticas no han sido recogidas sino en glosarios de distintas publicaciones endoinstitucionales.

En su primera acepción, la voz introduce un sentido jerárquico para distinguir entre los distintos tripulantes y es equivalente al sintagma jefe de cabina, tal como muestra el ejemplo 24 referido a la tripulación del avión papal ${ }^{19}$. En este sentido, alude a la tercera función profesional del colectivo, la de autoridad, pues, durante la operación aérea, este tripulante representa al comandante de la aeronave ante los pasajeros y el resto de la tripulación de cabina.

En cuanto a los primeros empleos, se registran también en la década de 1950:

(26) El Litoral 19551209, p. 3: El vuelo inaugural se inició en Ezeiza a las 8, siendo conducido el aparato por el comandante Luis Giménez, con la siguiente tripulación: copiloto Raúl Horcada, radio-operador Oscar Ciardelli y comisario R. Demarco («Quedó inaugurado esta mañana el servicio de Aerolíneas Argentinas para nuestra capital»).

La segunda acepción, el empleo de comisario para referirse a los TCP varones, es una alternativa para evitar la forma azafato y se puede apreciar en el siguiente ejemplo de Colombia:

(27) [CREA], El tiempo, 19750114: El proyectil abrió un gran agujero en el fuselaje del avión, debajo de su ala izquierda, e hirió a un comisario de a bordo y a un policía francés. Una camarera del avión se desmayó por la impresión («Fracasó ataque de palestinos»).

Mientras que a la mujer se la designa como camarera, el hombre recibe la denominación de comisario, aunque el indefinido un en lugar del determinante el sugiere que el tripulante aludido es uno más de la tripulación, y no (necesariamente) el de mayor

${ }^{19}$ En tal sentido, distintas compañías aéreas optan por una u otra denominación. Así, por ejemplo, en Argentina, algunas compañías seleccionan la denominación según el vuelo sea de cabotaje, en cuyo caso contará con un comisario de a bordo, o internacional, que tendrá un jefe de cabina. Por su parte, una nota de la asociación de tripulantes de España señala en 1983 que Iberia prefería para esta jerarquía la denominación sobrecargo y el resto de las compañías españolas jefe de cabina. 
rango. Junto con el ejemplo 24, entonces, este fragmento sugiere que ya en la década de 1970 se prefería contar con denominaciones diferentes según el género del personal.

En la actualidad, esta forma se ha registrado oralmente en hablantes de más de 50 años y también entre algunos jóvenes para designar a los tripulantes masculinos, aunque esto no sea aceptable en las organizaciones aéreas (cf. ejemplo 33). Desde su perspectiva, ambas acepciones pueden relacionarse con el desarrollo gradual de un conflicto laboral entre hombres y mujeres al interior de las organizaciones aéreas. Por muchos años, sólo los hombres resultaban elegibles como autoridad y así, si había (al menos) un hombre, este sería necesariamente el tripulante con mayor jerarquía. Así lo formula recientemente la Asociación Argentina de Aeronavegantes ${ }^{20}$ :

(28) El primer gran tema fue el comisariato femenino. En la historia de los tripulantes de cabina siempre hubo más nombres de mujeres que de varones y, sin embargo, su techo en la profesión era expresamente más bajo que el de los hombres. Todavía hoy el género es materia de reivindicación [...] // Durante años de vuelo observó que esas mujeres -"que convertían al galley en un microcosmos donde reinaban el orden y la pulcritud"- debían seguir, de modo inapelable, bajo las órdenes de los comisarios varones, aunque tuvieran menos méritos o experiencia. "Fue alrededor de esa injusticia que unas pocas tripulantes — creo que trece- nos reunimos para articular y potenciar ese reclamo. A partir de allí vimos la necesidad de organizarnos. Ganamos la primera causa: hoy hay mujeres comisarias y jefas de cabina" (Asociación Argentina de Aeronavegantes, 2008, p. 23-25).

De esta manera, puede pensarse que la segunda acepción se corresponde con estereotipos sociales sexistas que circulan tanto al exterior de las compañías de aviación — de ahí sus actuales empleos exo-institucionales - como en su interior — donde se la rechaza-

hostess. (Angl., pronunc. corriente/xós-tes/). f. azafata [DEA]. Frec. preced. por air o flight $\sim$. - DEA.

Solamente incluido en el DEA, el anglicismo (air/flight) hostess se registra en fuentes españolas desde mediados de la década de 1940. Es sabido que la inclusión de voces del inglés, con frecuencia, señala la novedad del referente y su vinculación con el progreso tecnológico. En este caso, también refuerza la idea de internacionalización como rasgo distintivo del transporte aéreo de posguerra. En este sentido, las comillas destacan el carácter de préstamo de la expresión, como en esta publicidad de la compañía TWA aparecida en la edición sevillana del diario $A B C$ :

(29) ABC-S 19460714, p. 14: Servicio de «hostess» en todos los vuelos al Este y Oeste de Madrid («Ahora, dos rutas al ESTE!!»).

$\mathrm{Su}$ empleo se constata en España y en distintas regiones hispanoparlantes, como lo demuestra este ejemplo del escritor peruano A. Bryce Echenique de 1970:

(30) "Le mete al trago", comentó uno de los del barrio, al ver que a Susan le servían la copa de jerez, otro ya iba a decir que a lo mejor como la flight hostess... pero en este instante aparecieron las chicas y ellos dieron una pitada indiferente y empezaron a

\footnotetext{
${ }^{20}$ La voz comisariato, por su parte, se registra en el ámbito de uso institucional y, en términos de la organización jerárquica de las tripulaciones de vuelo, es análoga a comandancia.
} 
disimular, recordando lo del gringo además, ya no tardaba en irse a cambiar, fumen, muchachos, fumen (Bryce Echenique, 1996[1970]: 300 [CORDE]).

Su empleo se registra hoy en forma muy ocasional, como lo ilustra esta nota del diario argentino Clarín, aunque aparece como un adjetivo:

(31) Clarín 20071004: "Es mi bautismo de vuelo", informa una estudiante. "Puedo decir que he volado", afirma una señora acompañada por una nena. "Ella ahora sabe como [sic] deberá comportarse cuando viaje". // Las chicas hostess reciben felicitaciones y piropos mientras reparten snacks. Afuera se escuchan los motores de los aviones que parten y aterrizan ( «Un vuelo de los sueños en el avión indio que no despega jamás»).

El destacado de hostess, esta vez en itálicas, sugiere que todavía sigue existiendo conciencia social sobre su carácter de préstamo.

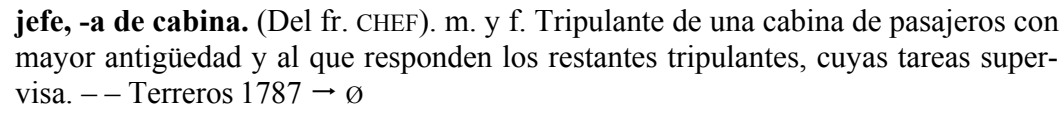

Si bien la voz jefe corresponde a un galicismo del siglo XVIII, no aparece la construcción con significado aeronáutico en los diccionarios que manejamos para este trabajo, aunque sí en glosarios en línea de léxico aeronáutico. Como comisario, -ria, se emplea tanto en el seno de las organizaciones aéreas que la seleccionan como en la sociedad para señalar el cargo de mayor jerarquía de una tripulación de cabina en un vuelo determinado. Sin embargo, a diferencia de lo que ocurre con la segunda acepción de comisario, - a de vuelo, no puede emplearse como denominación genérica ni de los tripulantes masculinos ni de los femeninos.

En el caso de España, una nota de la publicación Blanco y Negro sugiere que el cargo y sus funciones fueron formalizados como un rol masculino en la compañía Iberia hacia 1969 y este constituye el primer ejemplo de uso que hemos encontrado hasta el momento:

(32) Blanco y Negro, 19690111, p. 10: Iberia, nuevo puesto: "jefe de cabina" // Es objetivo de Iberia, para este año, completar la implantación de la nueva uniformidad en el vestido de las azafatas y extender a todos los vuelos, tanto nacionales como internacionales, el servicio "Rosa Real". Este servicio se instauró primero en los vuelos a Nueva York. Después se ha implantado en los servicios México y Centro y Sur de América. // Para coordinar la actuación de la tripulación auxiliar se ha creado el puesto de "jefe de cabina", a quien distinguirán los pasajeros por el "smoking" color granate, en contraste con el de color crema que llevará el resto de los auxiliares en el servicio "Rosa Real". A él podrán dirigir sus sugerencias los pasajeros («Correo aéreo»).

La relación entre el jefe de cabina y los pasajeros está marcada por su doble función como responsable de los tripulantes de cabina y por representar la autoridad legal del comandante de la nave tanto. Ante los restantes TCP, por su parte, es también figura de autoridad, aunque no deja de cumplir también funciones generales de la profesión.

En cuanto al género, la existencia de las dos formas en el uso actual (cf. ej. 34) muestra, como en el caso de comisario, - $a$, la igualdad de posibilidades de desarrollo para hombres y mujeres, enfatizada por el siguiente fragmento de Peña: 
(33) Quería ser azafato, asistente de vuelo, después llegaría a comisario. Y esta aclaración es muy necesaria: no todo hombre asistente de vuelo es comisario de abordo (sic): es asistente de vuelo, liso y llano. Después uno se convierte en comisario de abordo (sic) o jefe de cabina, eventualmente. Y se puede ser hombre o mujer. Durante toda mi carrera de vuelo, y aún hoy, la gente no sabe cómo denominarnos, siempre me preguntan: "Vos eras piloto, ¿no? Vos eras comisario de avión, ¿no? Vos eras azafato, ¿no? Vos eras comandante, ¿no? Vos eras camarero de cabina, ¿no?... "Chicos: no sean boludos, no es tan difícil. Es así: // Piloto (puede ser mujer u hombre) // Copiloto (puede ser mujer u hombre) // Jefe de cabina (puede ser mujer u hombre) // Asistente de vuelo (puede ser mujer u hombre) (Peña 2007:40).

purser. (Angl., pronunc. corriente /púr-ser/). com. Desus. jefe, -a de cabina. ---

Se trata de un anglicismo tomado del ámbito náutico, en el que designaba originalmente al 'tripulante de un barco responsable de administrar el dinero a bordo'. Sin registro lexicográfico español, este préstamo nos ha sido referido por hablantes de entre 60 y 70 años de edad, quienes recuerdan haberla empleado durante la década de 19601970. En el corpus actual no hemos podido registrarla en la prensa escrita hispanoamericana y el único ejemplo escrito corresponde a una entrada de un blog español dedicado a la aviación:

(34) Aerum 20100614: Cuando subimos al avión o bajamos del mismo lo que estamos haciendo es embarcar y desembarcar. En el avión nos encontramos con las azafatas o TCP (Tripulante de Cabina de Pasajeros) y los pilotos que, a su vez, son la tripulación auxiliar y la tripulación técnica respectivamente. // Esta tripulación técnica la suele componer el piloto y el copiloto que también se les llama capitán (o comandante) y first officer. También podemos escuchar que en la tripulación auxiliar, la de los TCP, hay una jefa de cabina que también se llama purser. // También a toda la tripulación, en su totalidad, se le llama crew («Aviación: Un poco de vocabulario»).

sobrecargo. (De SOBRE y CARGA, y esta de CARGAR. Del lat. vulg. CARRICĀRE, y este del lat. CARRUS, 'carro', del galo CARROS). com. Tripulante de avión que tiene a su cargo supervisar diversas funciones auxiliares [DRAE]. - - DRAE-1817 DRAE -1984 2. tripulante de cabina de pasajeros. - -

También se trata de una voz que proviene del ámbito marítimo y que, según el BDE, se remonta a mediados del siglo XVI. En dicho contexto designa al 'tripulante responsable de la carga'. Registrada en diversos diccionarios con acepción náutica (DEA, DPD, DRAE, DUE), los ejemplos de uso que evidencian la ampliación semántica de la voz y trasladan al ámbito aeronáutico el sentido de responsabilidad y supervisión, se constatan desde fines de la década de 1950. El primer caso que registramos se remonta a 1958, aunque podría adscribirse a cualquiera de las dos acepciones que hemos identificado:

(35) ABC-S 19581107, p. 37: El sobrecargo del aparato, Amado Cantillo, es hijo del general Eulogio Cantillo, jefe de las fuerzas del Ejército cubano que combaten contra los rebeldes de Fidel Castro ( «Un avión comercial cubano hubo de aterrizar en territorio rebelde»).

Con posterioridad, en la década de 1970 , se identifica claramente la primera acepción, en el siguiente ejemplo tomado del DEA:

(36) [DEA], Cela, Informaciones 19760315, p. 18: La mar está sosegada y el cielo azul, con unas nubecillas blancas y algodonosas que, al cruzarlas, hacen bailar un 
poco el aeroplano... A los diez minutos se me acerca el sobrecargo (el jefe de los auxiliares de vuelo).

La equivalencia semántica con comisario de a bordo y jefe de cabina se mantiene hasta la actualidad, aunque esta voz es común para el femenino y el masculino:

(37) La Nación 20030805: [...] El comisario de a bordo fue apresado anoche, al descubrirse que llevaba la droga oculta en dos hélices de madera para aviones ultraligeros que iba a embarcar en la bodega de la aeronave con destino a la capital española, indicaron. [...] // El sobrecargo ha sido acusado de tráfico internacional de drogas en unas actuaciones que quedaron en manos del juez federal en lo Penal Económico Julio Cruciani («Ezeiza: detienen a un sobrecargo que quería llevar cocaína a España»).

La segunda acepción carece de significado de autoridad, como muestran los siguientes ejemplos de Venezuela y Chile:

(38) El Nacional 20130310: Como en toda carrera, los ascensos se suceden regularmente. Los rangos son: aeromoza de turista o sobrecargo, aeromoza de primera clase, jefe de cabina de turista, jefe de cabina se primera clase y, finalmente, coordinador general («La glamorosa vida de las aeromozas»).

(39) Las Últimas Noticias 20121021: Sobrecargo, auxiliar de vuelo, tripulante de cabina, azafata o azafato, aeromoza o aeromozo, llámelo como quiera. Lo claro es que LAN necesita para el próximo año sumar a 207 personas para ese cargo y ya empezó el reclutamiento. [...] // El 30\% de los sobrecargos son hombres, en una carrera que por mucho tiempo se veía como femenina («LAN busca a 207 personas para trabajar como auxiliar de vuelo»).

Así, el empleo de sobrecargo para designar de forma genérica a un tripulante de cabina, hombre o mujer, se constata en la prensa de diversos países de habla española.

steward, -dess. (Angl., pronunc. corriente /es-tí-ward/ y /es-tí-war-des/). m. y f Desus. tripulante de cabina de pasajeros. Frec. preced. por air $\sim$ oflight $\sim$. - $\varnothing$

Hasta donde llega nuestro conocimiento, este anglicismo no fue recogido en diccionarios de la lengua española, aunque sus ejemplos de uso se remontan, también a la década de 1950 (cf. tb. ejemplos 46, 47 y 53 infra) y los hablantes de entre 60 y 70 años de edad recuerdan en entrevistas que era voz frecuente aunque un poco $s n o b$ en la Argentina. En la década posterior la registramos, por ejemplo, en la narrativa del escritor argentino J. Cortázar, quien emplea tanto la forma masculina como la femenina en el relato «La isla a mediodía»:

(40) Sonaba brevemente un timbre y el steward se enderezó, sin que la sonrisa profesional se borrara de su boca de labios finos. Empezó a ocuparse de un matrimonio sirio que quería jugo de tomate, pero en la cola del avión se concedió unos segundos para mirar otra vez hacia abajo; la isla era pequeña y solitaria, y el Egeo la rodeaba con un intenso azul que exaltaba la orla de un blanco deslumbrante y como petrificado, que allá abajo sería espuma rompiendo en los arrecifes y las caletas. [...] Durante la escala de Beirut miró el atlas de la stewardess, y se preguntó si la isla no sería Horos (Cortázar 1966: 93-94).

Como veremos en la sección 3, esta expresión fue tomada como punto de referencia inglés en la discusión de las denominaciones posibles en español sobre la base de las funciones de servicio que entraña la profesión (Casares 1950a: 3). 
TCP. (Acrón., pronunc. corriente/te-se-pé/). com. Endo. tripulante de cabina de pasaje-

ros. $--\varnothing$

Originada en el interior de las organizaciones aéreas, entorno que favorece especialmente el empleo de siglas (de- Matteis 2006), esta expresión no está recogida como acrónimo en los diccionarios pero aparece en forma ocasional, aunque cada vez más, en la prensa escrita hispanoamericana, por lo general entre paréntesis tras la forma desplegada, como se aprecia en el ejemplo 42 que reproducimos más abajo.

Como la forma desplegada, evita en el discurso la problemática del sexismo y la fuerte presencia de los acrónimos en la terminología aeronáutica permite sugerir un sentido de máxima profesionalización al no priorizar ninguna de las funciones de la actividad por encima de las otras.

tripulante (de cabina (de pasajeros)). (De TRIPULAR). com. Persona que integra la tripulación de un avión y vela por la seguridad de sus pasajeros al tiempo que se ocupa de su comodidad y atención. - - Domínguez $1853 \rightarrow \varnothing$

Aunque el diccionario de Domínguez recoge la voz tripulante en 1853, la acepción aeronáutica no es precisada posteriormente en ninguna de las fuentes lexicográficas consultadas. Sin embargo, la definición de tripulante remite a la de tripulación, entrada bajo la cual ya el $D R A E$ de 1925 incluye la posibilidad de una tripulación aérea. Con acepción aeronáutica, la voz tripulación puede ser calificada con el adjetivo técnica y el complemento de vuelo, para referirse a quienes pilotan la aeronave en cuestión, o con los complementos de cabina (de pasajeros) o el adjetivo auxiliar (de vuelo) para el personal auxiliar.

Como denominación surgida y preferida dentro de las organizaciones aéreas, la expresión se registra ya en la década de 1980:

(41) $A B C$ 19831227, p. 14: Ya en el año 1976 esta Cooperativa envió una carta publicada en ese diario para aclarar que nuestro grupo laboral tiene la denominación de «auxiliares de vuelo», divididos, según el sexo de cada uno de ellos, en femeninos y masculinos, y sobrecargos, en la Compañía Iberia, y jefes de cabina en las demás Compañías nacionales, que son miembros de la tripulación auxiliar con una determinada responsabilidad en su labor. En ningún caso, el término «azafato», que se utiliza en el mencionado artículo, define nuestra profesión. // La nomenclatura exacta que figura en nuestra licencia de vuelo de Aviación Civil es «tripulante de cabina de pasajeros». —-Joaquín Veiga. Cooperativa de Auxiliares de Vuelo. Algete. (Madrid) («Auxiliares de vuelo», carta del lector).

El autor de esta carta defiende la terminología empleada al interior de las compañías aéreas por encima de las denominaciones empleadas mayoritariamente en la comunidad, lo que pone en evidencia que, para los profesionales, sintagmas como asistentelauxiliar de vuelo y, sobre todo, tripulante de cabina jerarquizan la actividad, pues designan a los sujetos como miembros activos de una tripulación. En tal sentido, pilotos, copilotos, ingenieros de vuelo y auxiliares comparten el rol de tripulantes.

En el proceso de jerarquización profesional que traduce esta denominación, por otro lado, jugó un papel importante el reconocimiento de las organizaciones aeronáuticas a la función de seguridad que cumplen estos profesionales y que, con creciente frecuencia, comienza a reflejarse también en el lenguaje de la prensa escrita: 
(42) La Nación 20031228: Para el Instituto Nacional de Aviación Civil son tripulantes de cabina de pasajeros (TCP); para las aerolíneas, auxiliares de a bordo y para los turistas, las azafatas. // Sin embargo, cuando se las llama así-, ponen la misma cara de disgusto que los coiffeurs cuando se les dice peluqueros. "Nuestro trabajo no sólo consiste en dar y retirar bandejas, sino sobre todo ocuparnos de la seguridad de los pasajeros", aclara Florencia Temperley, TCP de Southern Winds (SW) desde 1998 («Azafatas, anfitrionas de los cielos»).

Por otra parte, los ejemplos de uso muestran que, en la acepción que nos interesa, la voz tripulante puede aparecer sola o acompañada de los complementos especificadores de cabina o la secuencia más precisa de cabina de pasajeros:

(43) Un tripulante en un avión es multifuncional. Yo dividiría sus tareas en tres estratos (Peña, 2007:88)

(44) La voz de Galicia 20121118: El comandante demandó la presencia de las fuerzas del orden en la aeronave porque un tripulante de cabina le había indicado previamente que había sido insultado por el citado pasajero y que por ello se consideró necesario que el hombre desembarcase por razones de seguridad («Expulsan de un avión de Ryanair a un pasajero por discutir con un azafato»).

Finalmente, el sintagma permite evitar — como asistentelauxiliar de a bordo/de vuelo y sobrecargo - todos los valores representacionales que estereotipan a la profesión, destacando la integración de los sujetos que la ejercen, con independencia de su género, como miembros de una tripulación, con tareas relevantes para alcanzar los objetivos institucionales de trasladar personas de forma segura y eficiente por vía aérea garantizando su lealtad como clientes.

\begin{tabular}{|l|l|l|}
\hline VOZ & OCURRENCIAS & $\%$ \\
\hline aeromozo, -a & 31 & 7,71 \\
\hline asistente de vuelo & 4 & 0,99 \\
\hline auxiliar (de a bordo, de vuelo) & 16 & 3,98 \\
\hline azafato, -a & 204 & 50,75 \\
\hline cabinera & 5 & 1,24 \\
\hline camarero, -a & 2 & 0,50 \\
\hline comisario, -a (de a bordo) & 22 & 5,47 \\
\hline hostess ${ }^{*}$ & 1 & 0,25 \\
\hline jefe, -a de cabina & 9 & 2,24 \\
\hline Sobrecargo & 14 & 3,48 \\
\hline (air) steward, -dess & 0 & 0 \\
\hline TCP & 36 & 8,96 \\
\hline tripulante (de cabina (de pasajeros)) & 58 & 14,43 \\
\hline Total & $402^{* *}$ & 100 \\
\hline
\end{tabular}

TABLA 3. Frecuencias léxicas para el periodo 1990-2013 en prensa escrita en español. ${ }^{*}$ Usado solamente como adjetivo. ${ }^{* *}$ Sobre el total de 753846 tokens.

Para finalizar esta sección, la comparación de las frecuencias relativas de todas las voces relevadas (tabla 3 ) indica que, aunque todavía hoy azafato, - $a$ es la voz más empleada (con poco más del $50 \%$ de las ocurrencias), va ganando lugar la denominación promovida desde el entorno endo-institucional de tripulante (de cabina (de pasajeros)). Considerada en forma conjunta con su acrónimo TCP, estas expresiones superan el $23 \%$ 
de las ocurrencias, lo que impide marcarlas como de uso endo-institucional. Si se tiene en cuenta que esta denominación se promueve desde hace aproximadamente unos treinta años, frente los más de 80 que tiene la profesión, la frecuencia de uso alcanzada es significativa aunque resulta difícil predecir si logrará igualar en su aceptación social a la de azafato, $-a$. En relación con la alternativa aeromozo, $-a$, aunque parece haber sido ya superada por tripulante de cabina, las diferencias con que están representadas las distintas variedades americanas dificultan evaluar el significado de su frecuencia relativa.

\section{DISCUSIÓN: VALORES REPRESENTACIONALES EN LA OPINIÓN DE LOS EXPERTOS}

Desde el nacimiento de la profesión de TCP y, en especial, durante las décadas de 1940-1950, la prensa escrita dio a conocer la opinión de reconocidas figuras de la filología española, en particular, de la peninsular, quienes propusieron y valoraron distintas alternativas léxicas, ocupándose de ellas con diversa profundidad. Estas reflexiones lingüísticas, sin embargo, no se agotaron en ese período y se ha retomado de forma esporádica hasta no hace mucho. Los textos que analizamos en esta sección corresponden a notas aparecidas en el diario español $A B C$ y se han seleccionado, en todos los casos, a partir de su hemeroteca digital.

Como resulta esperable, entre los argumentos reiterados en el tiempo, un eje central de la discusión es el de la defensa del español y sus recursos frente a las influencias foráneas. A título de ejemplo, aparece con claridad en el siguiente fragmento que, en el marco de una discusión más amplia, celebra el triunfo de una voz de larga trayectoria hispánica aunque de origen arábigo — azafata — frente a los anglicismos que todavía se empleaban en la década de 1960 para designar la profesión:

(45) Creo que hay que dar la voz de alarma ante el desorden con que hablamos y escribimos nuestra lengua; ante la impropiedad de tanto vocablo como prolifera en nuestro lenguaje «coloquial»; ante la penetración en tromba de innecesarios extranjerismos —que están llenando Madrid, por ejemplo de «snack bars», «dry cleanings», «antique shops»y otras paletadas parecidas-; ante el «invento» de palabrejas como esa de «aparcar», o aquella de «señalizar» — cuando existe el honrado verbo «señalar»-, o la otra de «aeromoza» — cuando ha triunfado ya el antiguo y rejuvenecido vocablo "azafata»-; ante la barbarie idiomática que nos amenaza a través de eso que se llama «los medios audiovisuales», o a través de traducciones infectas o «doblajes» atolondrados; ante la simple ignorancia de nuestro propio idioma, que nos está llevando, como un día decía el profesor Criado de Val, a un empobrecimiento del mismo y a una pérdida en virtud de la cual ya no distinguimos entre un olivo, un ciprés y un pino, y entonces decimos, simple y bárbaramente, «árbol» (Serna 1965: 88).

En relación con las causas de su éxito, J. M. Peman lo atribuye a la facilidad que entraña su configuración fonológica frente a las alternativas de préstamo:

(46) Apenas se cuentan, con los dedos, como éxitos académicos, la sustitución, a tiempo, de "speaker" por "locutor", la de "referee" por "árbitro" y la de "stewardess" por "azafata": palabra romántica y rebuscada, pero que, con su fácil despliegue de aes, gustó para no tener que usar la voz inglesa de tan dificultosa fonética para nosotros; de modo que al componerla y usarla daba tiempo para que se enfriara el café que a la azafata le pediamos (Peman 1966: 3). 
El éxito en la revitalización de esta voz y su amplia aceptación social se siguen celebrando, aún en fecha posterior:

(47) Pocos jóvenes sospechan hoy que la parrilla de un hotel se llamaba «grill», como en Escocia, y que la palabra azafata era entonces un fósil en el diccionario. Todo el mundo decía «stewardess», algo estupendo, chic, americanísimo. Los arqueólogos descubrieron lo otro: «Azafata: criada que servía a la reina los vestidos y alhajas.» La carcajada fue nacional: nadie daba un céntimo por la vida de semejante antigualla a bordo de los Metropolitan y los Constellation. Pues ahi está azafata: alegre, pimpante, juvenil, como las chicas que asi llamamos, a bordo de los Jumbo y los DC 10 (Calleja 1980: 3).

Sin embargo, para nuestros propósitos resultan más interesantes los argumentos centrados en las ideas que cada expresión reproduce y refuerza en su empleo social, pues nos permiten entender la relación entre la aceptación y frecuencia de uso de cada una de ellas. Entre los argumentos formulados por los distintos especialistas, las referencias a los ejes representacionales que hemos identificado en torno a las funciones desempeñadas y el género, se suman también a las consideraciones sobre el prestigio social de la profesión, aspecto que, como un tercer eje en la consideración de los factores sociales que han influido en el derrotero de las distintas alternativas léxicas estudiadas, resulta insoslayable. Atendiendo, entonces, a estos tres ejes, la discusión se manifiesta muy rica y permite apreciar sus interrelaciones diacrónicas, mostrando distintos aspectos del desarrollo progresivo del estereotipo social dominante y los esfuerzos para contrarrestarlo.

Si se consideran, en primer lugar, los vínculos entre el prestigio social y la función profesional, aquellas voces, que por su conformación morfológica o su significado habitual en la lengua, aluden directamente a la función de brindar servicio, afectan a las expectativas sociales que podrían tener las mujeres buscadas para ejercer la profesión, sobre todo en las décadas más glamorosas y exclusivas del transporte aéreo comer$\operatorname{cial}^{21}$. Como anticipamos en la sección precedente, esta tensión entre servidumbre y formación resultó importante para el derrotero de las expresiones aeromoza, azafata y camarera:

(48) La palabra es bonita. Y está recién nacida. Es americana de origen. "Aeromoza", la señorita sirviente en un avión. [...] Las horas de vuelo creo que resultan bastante aburridas, pese a la amabilidad y gentileza de las "aeromozas", cuya misión es atender a la alimentación de los viajeros, amén de otros servicios, todos ellos relacionados con la mayor comodidad del pasaje (Díaz-Cañabate 1947:9).

En este contexto histórico, en el que la profesión es una novedad, Díaz-Cañabate no cuestiona el empleo de la voz aeromoza, «la señorita sirviente en un avión», a la que vuelve a celebrar al final de su nota con la exclamación «“"Aeromoza”, linda palabra recién nacida!», pero solo tres años después, J. Casares la rechaza, calificándola de «engendro»:

${ }^{21}$ Los historiadores aeronáuticos concuerdan en considerar al período 1945-1970 como la «época dorada» de la aviación comercial. Con las crisis posteriores del mercado aeronáutico, las políticas de desregulación y otros cambios sociales, el transporte aéreo se popularizó y perdió parte de ese «glamour». 
(49) No se han registrado, en efecto, nuevos engendros del tipo "muchadavi", "aeromoza", etc., y ésta era una de las finalidades, por no decir la principal, que me movieron a tomar la pluma (Casares 1950b: 3).

Esta descalificación ocurre en el contexto de su aporte al «pleito de las señoritas en busca de nombre», que se plasma en dos notas del diario $A B C$, «Una tremenda desorientación» (28 de mayo) y «Punto redondo» (24 de junio), en las que discute las distintas alternativas léxicas que se habían propuesto ${ }^{22}$. Sus textos también destacan esta única función profesional como criterio semántico para encontrar la denominación apropiada $^{23}$ y sugiere que la idea de moza podría asociarse con tareas «humildes»:

(50) Yo creo que en la rica gradación de los nombres con que se venía designando a la mujer que presta servicios auxiliares a otras personas, desde la "moza" que desempeña humildes menesteres en un mesón hasta la dama linajuda, que se honra con el título de "azafata", no faltará alguna denominación aplicable a esas "servidoras en busca de nombre", cuyas funciones no difieren esencialmente de otras análogas sino por razón del lugar en que se ejecutan (Casares 1950a:3).

Como puede apreciarse, por estos años, la función de atender a la seguridad de la cabina, que hoy es el argumento central empleado por los TCP para jerarquizar su tarea, no era considerada en la discusión, puesto que tampoco dentro de las organizaciones aéreas se le asignaba una importancia significativa. En cambio, sobre todo en los textos de Casares, el prestigio social derivado de las funciones de la profesión evocadas por cada voz sí tiene un lugar preponderante en la discusión. Las tareas de servicio contradecían especialmente las expectativas de reconocimiento social de las tripulantes porque, aunque «sirviendo» a bordo, poseían un alto nivel de cultura, reconocido, por ejemplo, en la reiterada referencia a su habilidad para dominar diversas lenguas:

(51) Lo cierto es que la azafata se aclimató perfectamente en nuestro país y ahora podemos contemplarlas en vuelo o en cualquier acontecimiento de nuestra vida política, comercial o social, con la sonrisa en los labios y la justa información, con su voz vernácula o hablando aquellas lenguas de mayor auge diplomático o comercial (Manrique de Lara 1971: 23).

Puede concluirse, entonces, que el prestigio social constituye uno de los factores que influyó en la preferencia general por azafata frente a aeromoza y camarera, al menos en el contexto peninsular, y aunque el mismo Casares recuerda a quienes pudieran objetar la forma camarera sobre el argumento de la servidumbre que, a diferencia

${ }^{22}$ «Debemos, pues, a la iniciativa privada tres denominaciones, "aeromoza", "aviatriz" y "muchadavi", a reserva de que existan otras creaciones de las que no he tenido noticia. La Academia se ha abstenido de terciar espontáneamente en el debate; pero hace ya quince años recibió un escrito ofícial de cierta compañía de líneas aéreas, en el que se pedía una equivalencia castellana de la voz "Stewardess", aplicada en inglés a las servidoras cuya misión se especificaba. La Academia propuso "provisoras" y, aunque la empresa aceptó muy agradecida la solución, lo cierto es que no ha trascendido al uso común.» (Casares, 1950a: 3). Además de estas alternativas, en la nota del mes de junio resume otras que considera más válidas: mayordoma, provisora, camarera y azafata.

${ }^{23}$ Casares contempla también criterios pragmáticos, como la (im)posibilidad de usar una voz como vocativo, y actitudinales como la defensa del español a partir de la preferencia por traducir las expresiones del inglés. 
de aeromoza, esta voz tiene una acepción que, sin negar la idea de servicio, supone un reconocimiento social:

(52) Si a los varones de mi quinta esta denominación les recuerda ciertos cafés de nuestra juventud donde la servidumbre femenina no era lo que se dice huraña, no se olvide, en sentido opuesto, que "camarera" significa también la "servidora de más respeto de las casas principales" y que la "camarera mayor" de Palacio había de ser grande de España (Casares 1959b: 3).

Similares consideraciones se podían hacer $-\mathrm{y}$ se hicieron de manera reiteradasobre la voz azafata, destacando que su tarea original en la corte otorgaba prestigio y, por lo tanto, la voz connotaba esta misma idea de reputación, de dama «linajuda» en palabras de Casares (cf. ej. 50) o su «clásico abolengo», como señala el académico Fernández Almagro en una crítica literaria a una novela de 1955:

(53) La "stewardess" - azafata, aeromoza - comienza a frecuentar la novela de hoy, fiel al hecho normal de su aparición en la realidad inmediata. En este caso concreto, se trata de "Otros son los caminos", de Antonio Ortiz Muñoz, quien, por cierto, prefiere decir "aeromoza", contra el uso general de "azafata", vocablo más indicado, a nuestro juicio, por su clásico abolengo, fácilmente adaptable a esa nueva profesión femenina (Fernández Almagro 1955: 41).

Así, asociadas todas con la idea de servicio, azafata sería la voz que menos evocaría una idea de humildad, le seguiría camarera y el neologismo aeromoza se ubicaría en la última posición. Estas connotaciones se relacionan, al menos eso sugieren los textos, con posibilidades decrecientes de valoración social. Las observaciones precedentes son resumidas por Lázaro Carreter en fecha mucho más reciente:

(54) Entre nosotros, empezó a hablarse de «aeromoza», con poca aceptación: lo de «moza» no agradaba a las muchachas normalmente distinguidas, que empezaron ejerciendo profesión tan políglota. Tampoco camarera, por muy aeronántica que fuera, convenía a tanto riesgo - al principio - , privilegio y elegancia. Por el cual, alguien recordó el nombre de aquellas viudas aristocráticas que servían en la cámara regia, y «azafata» obtuvo un éxito inmediato: era cáscara vacía pero prestigiosa. Después, todos lo sabemos, ha servido para designar a las mujeres, casi siempre jóvenes, que desempeñan funciones análogas en otros vehículos o que acogen a visitantes o asistentes a determinadas reuniones (Lázaro Carreter 1992: 3).

La problemática de la jerarquización vinculada a la ampliación de las funciones profesionales no se registra en ningún momento de la discusión metalingüística y esto da cuenta del lugar central que la función de atención al pasajero tiene, aún hoy, en la representación social de esta actividad. En este sentido, la promoción de la denominación tripulante de cabina de pasajeros que los profesionales realizan desde fines de la década de 1970 en adelante, pone en evidencia el reclamo de un lugar diferente frente a las compañías aéreas y frente a la sociedad. Sus esfuerzos para que la expresión pase de ser una autodenominación a una voz aceptada por la sociedad demuestra las diferencias que existen entre la representación social y la «autorrepresentación» de este colectivo y sugiere que la nueva designación puede entenderse como un eufemismo profesional en tanto pretende resaltar aspectos de la imagen positiva de los sujetos a los que 
refiere, minimizando los potenciales rasgos negativos evocados por las denominaciones asociadas a una la central de servidumbre (Edeso Natalías 2009) ${ }^{24}$.

Además, y también presente en la discusión metalingüística, el eje del género se detecta en el hecho de que todas las expresiones aludidas en los fragmentos ya citados aparecen tienen género femenino, indicador suficiente de que la profesión se concebía para la mujer y no para los hombres. Sin embargo, aunque en las primeras décadas existían algunos auxiliares de vuelo de sexo masculino en algunas compañías, fueron los cambios sociales y los cambios profesionales los que permitieron y demandaron la introducción cada vez más frecuente de tripulantes varones. Este hecho introdujo un cambio en la representación social, pues ese ámbito ya no podía pensarse como exclusiva o mayoritariamente femenino, pero también introdujo tensiones a nivel interno pues, reproduciendo un pensamiento social extendido, a los hombres se les otorgaba mayor jerarquía y reconocimiento profesional. En tal sentido, ya hemos señalado en la sección precedente que la asociación de la voz comisario con la figura de autoridad masculina explica la existencia de una acepción específica para el tripulante de sexo masculino.

Estos cambios y problemáticas socioculturales se reflejan en la discusión lingüística en época más reciente, por ejemplo, en la voz de Lázaro Carreter, quien cuestiona el empleo de la forma masculina azafato:

(55) No existe nombre para el equivalente varón que, conforme a una igualación profesional de los sexos, ha accedido a tal oficio. Y muy en serio, aunque parezca broma, ha empezado a llamarse «azafatos» a los hombres. Lo oí primero en Sevilla, pero ya lo he visto escrito en varios sitios. Se trata de una masculinización estéticamente aberrante, aunque fuera posible desde el punto de vista morfológico: si sobre el nombre del objeto «azafate», se formó el nombre de la persona «azafata», bien pudo haberse formado «azafato» si el rey hubiera contado con un conde viudo, por ejemplo, que le ofreciera la vestimenta en bandeja. Pero ahora rechina tal formación. De no hallarse término mejor, ¿no cabría llamar «azafates» a los varones que desempeñan los mismos oficios que las azafatas? (Lázaro Carreter, 1992: 3).

Dando cuenta de los nuevos tiempos, la discusión de mediados de siglo XX podría haberse repetido, pero, hasta donde llega nuestro conocimiento, no ocurrió lo mismo. La forma masculina se aceptó ya en el DPD, tal como indicamos en la sección precedente y existen, además, alternativas como auxiliar de vuelo o tripulante de cabina de pasajeros que, preferidas por los profesionales, permiten solucionar las necesidades designativas cuando el hablante no percibe como apropiadas las formas masculinas como azafato.

Para finalizar, tanto la reflexión sobre esta forma masculina como también la aceptación lexicográfica de aeromozo dan cuenta de una situación particular e interesante en el marco de las consideraciones sobre el sexismo lingüístico de las denominaciones profesionales (Lledó Cunill 2006) pues las necesidades referenciales no sexistas conducen a la creación de una forma masculina para una profesión asociada a lo femenino y no a la inversa.

\footnotetext{
${ }^{24}$ Desde un marco general de cortesía verbal, Edeso Natalías (2009: 158) se refiere en este sentido a la denominación auxiliar de vuelo y observa que, como otros eufemismos de profesión, la expresión surge a través de un mecanismo de intensificación positiva que atenúa los posibles rasgos negativos de voces que, en sentido estricto, no son tabú.
} 


\section{CONCLUSIONES}

El análisis realizado permite elaborar algunas conclusiones de interés estrictamente lingüístico y otras relevantes para una historia de las representaciones sociales de la aviación. En el primer sentido, las voces que integran este sector del campo léxico de las profesiones aeronáuticas ilustran distintos procesos de creación léxica. Así, algunas provienen de la náutica (sobrecargo, tripulante) y han visto ampliado su significado al comprender al vuelo, metafóricamente, como una nueva modalidad de navegación. Camarero, $-a$, por su parte, también sufrió una ampliación semántica por una analogía de funciones de la casa o el establecimiento público al avión. También se registran derivaciones nuevas (cabinera) y un exitoso caso de revitalización léxica (azafata), que fue seguido de una ampliación semántica que permite su empleo en otros ámbitos. También se constatan unidades poliléxicas cuyo núcleo nominal proviene de expresiones de uso general en la vida social y hogareña (asistente, auxiliar, comisario, jefe, mozo, $-a$ ) y cuyo su significado se especifica mediante el prefijo \{aero- $\}$ o con complementos como de a bordo, de cabina o de vuelo. Finalmente, también se registran préstamos léxicos del inglés que, sin recibir adaptaciones al sistema español, cayeron en desuso ([air/flight $]$ hostess, purser, [air $]$ stewardess).

Pero la preocupación de los especialistas por la denominación de la profesión del TCP, desproporcionada en comparación con la de otras profesiones aeronáuticas, y el análisis de las distintas alternativas revelan que en el proceso de nominación para esta actividad intervienen no sólo consideraciones de tipo lingüístico, sino también cambios de naturaleza social ocurridos a ritmo acelerado durante la segunda mitad del siglo XX y lo que ha transcurrido del presente. Entre ellos, pueden mencionarse, en primer lugar, las modificaciones en las condiciones laborales específicas de los tripulantes, afectadas por los avances técnicos y el aumento del tamaño de las aeronaves, que demandan mayores niveles de capacitación y permiten el acceso masivo de la población a un medio de transporte, en sus principios, bastante exclusivo. Estos factores influyeron en un incremento y especialización de las funciones profesionales, al punto que la función de seguridad y autoridad pasan a ser prioritarias desde el punto de vista institucional y explican, en parte, el intento de los sujetos por jerarquizar su profesión desde el plano léxico con denominaciones que no limitan el espectro de funciones ejercidas a la del servicio al cliente (aeromozo, -a, azafato, -a, cabinera, camarero, - a).

En este mismo esfuerzo, influyen también los cambios en la representación social de la femineidad y la masculinidad, así como sus efectos a nivel de las actividades laborales desempeñadas por los sujetos. En el ámbito aeronáutico, esto se tradujo tanto en reivindicaciones jerárquicas del personal femenino, como en el borramiento de los límites entre lo que es una profesión para mujeres o para hombres. Así, la problemática del sexismo lingüístico se evidencia tanto en la selección entre las alternativas léxicas, como en el hecho de que para algunas expresiones, femeninas en su origen, se hayan creado opciones de género masculino (aeromozo, azafato). En ambos casos, su distinto grado de aceptación social puede evitarse mediante las denominaciones favorecidas por los colectivos profesionales de la comunidad hispanoparlante: auxiliar/asistente de vuelo y, sobre todo, tripulante de cabina de pasajeros. 
Resulta interesante e indicador de cambios culturales profundos que evitar las connotaciones sexistas que refuerzan los estereotipos sociales sobre la profesión constituya un interés compartido por tripulantes femeninas y masculinos. Sin embargo las reivindicaciones laborales basadas en cuestiones de género continúan. A título ilustrativo, puede considerarse el conflicto descripto en la siguiente noticia:

(55) El País 20110301: Así, apunta que la competencia sobre "la uniformidad de los trabajadores corresponde a la empresa, que no ha cambiado sus criterios desde el año 2000" y entonces decidió que las mujeres que trabajaran en ella "debían llevar siempre una falda". Hace 11 años debía ir "por debajo del hueso de la rodilla" y ahora, tras la actualización, se ha recortado "cinco centímetros por encima de la rodilla". Para CC OO esta imposición es "una clara manifestación de discriminación sexista en línea con la que se ejerce contra los hombres, a los que no se admite para desempeñar la profesión de tripulante de cabina" («CC OO denuncia que Air Nostrum prohíbe a sus azafatas llevar pantalones»).

Aunque la preferencia por las expresiones que evitan el sexismo lingüístico y jerarquizan la profesión sea absoluta al interior de las organizaciones aéreas y los datos de la tabla 3 sugieran que su extensión en los usos sociales cotidianos está avanzando, tal como sugieren este último fragmento y muchos de los ejemplos citados más recientes, no puede concluirse ni que el estereotipo femenino de la profesión, ni su vinculación prioritaria con la atención del pasajero ni los conflictos laborales asociados al género hayan sido completamente superados.

\section{REFERENCIAS BIBLIOGRÁFICAS}

BAKER, Paul (2006): Using corpora in discourse analysis, Londres, Continuum.

Berber SardinHA, Tony (2009): Pesquisa em lingüistica de corpus com Wordsmith Tools, Campinas, Mercado de Letras.

DE MATTEIS, Lorena (2006) «Las siglas en la interacción piloto/controlador en español bonaerense», en N. Flawia de Fernandez, S. Israilev, comps., Hispanismo: Discursos culturales, Identidad y Memoria, Tucumán, Universidad Nacional de Tucumán, III, pp. $328-339$.

(2012): «Expresiones de origen náutico en el nacimiento de las distintas formas de volar: aerostación, aviación y astronáutica», Literatura y Lingüistica, 25, pp. 275-298.

- (2010): «Navegación aérea y progreso: los textos de humor en el contexto del Centenario», en O. Aranda Durañona, ed., Centenario del vuelo mecánico 1919-2010. Actas del I Congreso de Historia Aeronáutica Argentina, Buenos Aires, Dirección de Estudios Históricos de la Fuerza Aérea Argentina, pp. 197-215.

DAVIS, Barbara y Alice MUSBACH (1985): Curso de auxiliares de vuelo, Madrid, Paraninfo.

EDESO NATALÍAS, Verónica (2009): «Revisión del concepto de eufemismo: una propuesta de clasificación», Revista Internacional de Lingüistica Iberoamericana, 2, pp. 147-163. 
ENRIQUE-ARIAS, Andrés, ed. (2009): Diacronía de las lenguas iberorrománicas. Nuevas aportaciones desde la lingüística de corpus, Madrid-Frankfurt, Iberoamericana/Vervuert.

FRITZ, G. (1988): "Change of meaning and change of vocabulary», en U. Ammon, N. Dittmar y K. Mattheier, eds., Sociolinguistics/Soziolinguistik, Berlín-New York, Walter de Gruyter, II, pp. 1614-1631.

JODELET, Denise (1993[1984]): «La representación social: fenómenos, concepto y teoría», en S. Moscovici, ed., Psicología social II, Paidós, Buenos Aires, pp. 469-494.

Lledó CUNILL, Eulàlia (2006): Las profesiones de la A a la Z. En femenino y en masculino, Madrid, Instituto de la Mujer/Ministerio de Trabajo y Asuntos Sociales.

LÜDTKE, Jens y Christian SCHMITT, eds. (2004): Historia del léxico español. Enfoques y aplicaciones, Madrid, Vervuert.

Medina Guerra, Antonia M. ${ }^{\mathrm{a}}$, coord. (2003): Lexicografía Española, Barcelona, Ariel.

SECO, Manuel (2003 [1987]): Estudios de lexicografía española Madrid, Gredos.

WAllingRe, Noemí (2003): Transporte aéreo en turismo, Buenos Aires, Ediciones Turísticas.

WODAK, Ruth y Michael MEYER, eds. (2001): Methods of critical discourse analysis, Londres, Sage.

WODAK, R. y Paul CHILTON, eds. (2005): A new agenda in (critical) discourse analysis, Amsterdam/Philadelphia, John Benjamins Publishing Company.

\section{FUENTES DOCUMENTALES}

\section{Primarias}

Argentina: los diarios La Nación, Clarín, Página 12, Río Negro, La mañana del Sur, La Nueva Provincia, Misiones online, Tiempo Argentino, El Esquiú, Jujuy al día, Diario de Neuquén, Los Andes, Diario de Mendoza, Territorio Digital, Diario de Jujuy, El Sol de Quilmes, La Opinión Austral, Diario del Fin del Mundo, La Razón, La Gaceta, Córdoba, Minuto Uno, Diario Uno, La voz del Interior; las revistas La Nación, Rolling Stone, Oh-Lala, Brando, Guía Argentina de Tráfico Aéreo y Revista Aeroposta; las páginas de Internet de Perfil, Aerolíneas Argentinas, ORSNA, Servicio de Prensa de la República Argentina, y los blogs «Skyscraper city» y «El Blog de Mili».

Bolivia: diarios El día, Los tiempos, El diario.

Chile: diarios Cooperativa, Las Últimas Noticias y el blog «Modo Charlie».

Colombia: diario Semana.

Cuba: diarios Prensa Libre y Escambray.

Ecuador: diarios Hoy y El Universal.

España: diarios ABC, El País, La Voz de Galicia, El ideal, Diario de Sevilla, Granada hoy, La Vanguardia, El Mundo, Diario de Cádiz, La Razón, Diario de Málaga, Huffington Post (edición española), Diario de Ibiza, El Imparcial, El Periódico, El correo digital, Preferente, El Heraldo de Aragón, La voz de Santiago, La voz de Almería, El día de Tenerife, El Adelanto de Zamora, Hora Sur, Salamanca 24 horas, La Opinión de Tenerife, Cinco Días, Público, Diario de Córdoba El montañés; la revista Elle; los blogs y foros «El viajero astuto», «Teleazafata», «Diario de una ex azafata de vuelo», «Extra Crew», «Blog de Aviación», «Altímetro 1040», «Surcando los cielos» y la página de Internet de AENA.

Estados Unidos: diario El Nuevo Herald. 
México: diarios El cronista, Hoy Tamaulipas, El Universal, Excelsior, La Crónica, La Vanguardia, Tribuna, El diario de México.

Paraguay: diario La Nación.

Perú: diarios La república, Caretas. Ilustración peruana.

Uruguay: diarios El pais y La red 21.

Venezuela: diario El Nacional y blog «Bitácora de un sobrecargo».

Asociación Argentina de AeronaVegantes (2008): El cielo es nuestro, Buenos Aires.

AYALA, Francisco (1990): «La agresividad», $A B C, 24 / 3 / 1990$, p. 3.

BRYCE ECHENIQUE, Alfredo (1996[1970]): Un mundo para Julius, Madrid, Cátedra [COR$\mathrm{DE}]$.

CAlleja, José Luis (1980): «De Méjico a México y vuelta», Diario ABC, 22/3/1980, p. 3.

CASARES, Julio (1950a): «Una tremenda desorientación», $A B C, 28 / 5 / 1950$, p. 3. (1950b): «Punto redondo», $A B C, 24 / 6 / 1950$, p. 3.

CORTÁZAR, Julio (1986[1966]): «La isla al mediodía», Todos los fuegos el fuego, Buenos Aires, Planeta.

SERNA, Alfonso de la (1965 [1964]): «Los periódicos y el idioma», en Boletín de la Dirección General de Archivos y Bibliotecas, 30/04/1965, p. 87-88. (Reproducido del ABC, 30/4/1964).

DíAZ-CAÑABATE, Antonio (1947): «Las «aeromozas»»», $A B C$, 29/6/1947, p. 9.

LÁZARO CARRETER, Fernando (1992): «Cónyuges y oficios nuevos», $A B C, 24 / 5 / 1992$, p. 3.

MANRIQUE De LARA, José (1971): «Azafatas», $A B C, 26 / 11 / 1971$, p. 23.

PEMAN, José Ma. (1966): «Una tímida propuesta», $A B C, 14 / 9 / 1966$, p. 3.

PIÑAR, Blas (1959): «Defensa del Español», $A B C, 27 / 3 / 1959$, p. 23.

VEIGA, Joaquín (1983): «Auxiliares de vuelo», $B C, 27 / 12 / 1983$, p. 14.

PeÑA, Fernando (2007): Gracias por volar conmigo, Buenos Aires, Sudamericana.

ZINA, Alejandra (2011): Barajas, Buenos Aires, Plaza \& Janés.

Lexicográficas

Academia Argentina de Letras, Diccionario de Habla de los Argentinos, Buenos Aires, Emecé Editores. [DHA]

Cayuela, Nuria Lucena (2002): Diccionario de uso del español de América y España, Barcelona, VOX. [VOX]

ChuchuY, Claudio y Laura Hlavacka De Bouzo coord. (1993): Nuevo diccionario de argentinismos, Bogotá, Instituto Caro y Cuervo. [NDA-ARG]

Corominas, Joan (2009): Breve diccionario etimológico, Buenos Aires, Del Nuevo Extremo. [BDE]

De SANTIS, Augusto (2007): Manual de Traducciones Aeronáuticas, Buenos Aires, edición del autor. [MTA]

Domínguez, Ramón Joaquín (1853): Diccionario Nacional o Gran Diccionario Clásico de la Lengua Española (1846-47), Madrid-París, Establecimiento de Mellado, $5^{a}$ ed., 2 vols.

MOLINER, María (2007): Diccionario de Uso del Español, Madrid, Gredos. [DUE]

NeBRiJA, Antonio de (c.1495): Vocabulario español-latino, Salamanca, Impresor de la Gramática castellana. [NEBRIJA]

Real Academia Española (200122): Diccionario de la Real Academia Española. En línea: http://www.rae.es. [DRAE] 
(2001): Nuevo Tesoro Lexicográfico de la Lengua Española. En línea: http://buscon.rae.es/ntlle/SrvltGUILoginNtlle. [NTLLE]

(2005): Diccionario panhispánico de dudas. En línea: http://www.rae.es/recursos/diccionarios/dpd. [DPD]

SECO, Manuel (1999): Diccionario del Español Actual, Madrid, Aguilar. [DEA]

TERREROS Y PANDO, Esteban de (1787): Diccionario castellano con las voces de ciencias y artes y sus correspondientes en las tres lenguas francesa, latina e italiana, Madrid, Viuda de Ibarra. [Terreros] 